DE

M E D I C I N A

T R O P I C A L

$\mathrm{DE}$

SÃO PAULO

JOURNAL OF THE SÃO PAULO INSTITUTE OF TROPICAL MEDICINE

1 Universidade do Estado de Mato Grosso, Faculdade de Ciências Agrárias e Biológicas, Programa de Pós-Graduação em Ciências Ambientais, Cáceres, Mato Grosso, Brazil

${ }^{2}$ Universidade Federal de Mato Grosso, Faculdade de Enfermagem, Programa de Pós-Graduação em Enfermagem, Cuiabá, Mato Grosso, Brazil

${ }^{3}$ Centro Brasileiro para o Cuidado à Saúde Informado por Evidências, Centro de Excelência do Instituto Joanna Briggs, São Paulo, São Paulo, Brazil

${ }^{4}$ Universidade de Cuiabá, Programa de Pós-Graduação em Ambiente e Saúde, Cuiabá, Mato Grosso, Brazil

${ }^{5}$ Universidade do Estado de Mato Grosso, Faculdade de Ciências da Saúde, Departamento de Medicina, Cáceres, Mato Grosso, Brazil

Correspondence to: Omar Ariel Espinosa Universidade do Estado de Mato Grosso, Faculdade de Ciências da Saúde, Departamento de Medicina, Av. Tancredo Neves, 1095, CEP 78200-000, Cáceres, MT, Brazil

Tel: +55 65 3221-0000

E-mail: oespinosa@usp.br

Received: 15 April 2019

Accepted: 15 July 2019

\section{Diagnostic accuracy of Enzyme-Linked Immunosorbent Assays to detect anti-Leishmania antibodies in patients with American Tegumentary Leishmaniasis: a systematic review}

\author{
Andernice dos Santos Zanetti ${ }^{1}$, Camila Massae Sato ${ }^{2}$, Fabiana Gulin Longhi ${ }^{3}$, \\ Silvana Margarida Benevides Ferreira ${ }^{2,3,4}$, Omar Ariel Espinosa ${ }^{(15}$
}

\section{ABSTRACT}

American Tegumentary leishmaniasis (ATL) is an infectious disease caused by several species of Leishmania. Even though the direct detection of parasites has low sensitivity, it is still the gold standard for the laboratory diagnosis of ATL. Recent studies have shown promising results of Enzyme-Linked Immunosorbent Assays (ELISAs) using recombinant antigens. The aim of this study is to compare the accuracy of ELISAs using novel antigens with the standard ELISA based on soluble antigens of Leishmania (SLA) to diagnose ATL. Studies that analyzed patients with ATL and studies that evaluated the diagnostic accuracy of ELISAs using novel antigens and SLA were included. The Fourteen studies from PubMed, Regional Portal of the Virtual Health Library (BVS), Brazilian Society of Dermatology, Virtual Health Library (IBECS), Literature in the Health Sciences in Latin America and the Caribbean (LILACS), Medical Literature Analysis and Retrieval System Online (Medline), Elsevier Embase, Cochrane Library, The National Institute for Health and Care Excellence (NICE), and Cumulative Index to Nursing and Allied Health Literature (CINAHL) were included. The novel ELISA antigens showed a high sensitivity $(93.8 \%-100 \%)$ and specificity (82.5-100\%), a better diagnostic performance than SLA-based ELISAs (1-97.4\% and $57.5-100 \%$, respectively). Only 10 studies analyzed cross-reactions in serum samples from patients with Chagas disease, and only two studies reported a percentage of cross-reactivity. In this systematic review, the novel ELISA antigens showed better sensitivity and specificity with respect to SLA-based ELISAs. However, a meta-analysis should be performed to confirm this finding.

KEYWORDS: American Tegumentary Leishmaniasis. ELISA. Accuracy. Diagnosis. Serology. Recombinant antigens. Novel antigens. Leishmaniasis.

\section{INTRODUCTION}

American Tegumentary Leishmaniasis (ATL) is an infectious disease that affects the skin and mucous membranes, showing distinct clinical manifestations determined by an equilibrium between parasitic factors (tropisms, virulence, resistance and species) and the host immune respons $\mathrm{e}^{1-3}$. The main clinical forms are cutaneous leishmaniasis (CL), muco-cutaneous leishmaniasis (MCL) and disseminated cutaneous leishmaniasis (DCL). The cutaneous leishmaniasis (CL) is caused by $L$. (V.) braziliensis, $L$. (V.) guyanensis, $L$. ( $L$.) amazonensis and $L$. (V.) naiffi. The muco-cutaneous leishmaniasis (MCL) is caused by $L$. (V.) braziliensis and the disseminated cutaneous leishmaniasis (DCL) is caused by $L$. (L.) amazonensis and L. (L.) mexicana $a^{4}$ 
According to the World Health Organization (WHO), leishmaniasis is one of the most important neglected tropical diseases due to its high detection coefficient and capacity to produce deformities. This disease affects mainly individuals of low socioeconomic level, and the number of cases in endemic areas have increased significantly in recent years ${ }^{5-8}$. It is estimated that 350 million people are at risk of contracting the infection, and the annual incidence is estimated at about two million new cases ${ }^{9}$.

In Brazil, about 20 thousand cases/year are recorded, with an incidence coefficient of 10.3 cases $/ 100,000$ inhabitants in the last five years. In 2015, the Brazilian North region had the highest incidence rate (51.1 cases/100,000 inhabitants), followed by the Midwest (19.0 cases/100,000 inhabitants) and the Northeast $(9.1 \text { cases/100,000 inhabitants })^{10}$.

The diagnosis of leishmaniasis is based on epidemiological data, clinical characteristics and laboratory test results, including parasitological examination, serological and molecular methods as well as the Montenegro skin test ${ }^{4}$.

Clinical practice guidelines recommend multiple testing of active cutaneous lesion samples. Thus, the parasitological diagnosis is based on the evidence of the parasite through direct microscopy of smears and/ or culture, requiring a trained laboratory $\operatorname{staff}^{11,12}$. In addition, these tests require invasive procedures of sample collection, which limit their use ${ }^{13}$. Even though the direct detection of parasites has low sensitivity, it is still the gold standard for the laboratory diagnosis of ATL. The Montenegro skin test (MST), with a sensitivity rate of $86.4-100 \%^{14}$, is the main diagnostic test in primary care. In the presence of a suspicious cutaneous lesion, MST supports the diagnosis of Leishmania infections. However, MST results may be influenced by the clinical presentation and the disease duration ${ }^{14}$.

The association of MST with molecular biology methods, especially in reference treatment centers, offers higher diagnostic accuracy as well as good sensitivity and specificity. Therefore, a combination of diagnostic methods is usually required to obtain accurate results ${ }^{15,16}$. There is a need to develop faster, more effective and simpler assays for the diagnosis of this disease ${ }^{17}$. Among these tests, serology has been the most widely used method in epidemiological studies, providing additional support for disease control measures. However, since most patients have low antibody titers against Leishmania species, this method may be associated with a relatively high proportion of false negative results. In addition, different species of Leishmania overlap the distribution of Trypanosoma cruzi in many geographic regions, increasing the risk of cross-reactions in these endemic areas ${ }^{18,19}$.
ELISAs are useful diagnostic tools for ATL, being fast and relatively affordable. However, their accuracy is variable $^{20,21}$. Several studies have selected proteins common to Leishmania species to develop an assay capable of detecting the disease irrespective of the etiological agent species. Among the proteins used, cytochrome c oxidase VII (CcOx), IgE-dependent histamine-releasing factor (HRF) and histones have been used ${ }^{21,22}$.

Recently, several recombinant proteins have been successfully developed and used for the serological diagnosis of ATL, showing better sensitivity and specificity. In ELISAs, the recombinant antigens rK108, rLbHyM, rLHHs, rHSPH83, RA2, rLb6H, and rLb8E were used ${ }^{23-27}$.

Promising results in several studies on ELISAs using recombinant antigens have been reported. The successful implementation of these methods reflects their good performance. Therefore, this study provides a brief systematic review of studies on the accuracy of available serological tests, aiming to evaluate the accuracy of these tests for the detection of antibodies against Leishmania species.

\section{MATERIALS AND METHODS}

The protocol of this systematic review was published in the International Prospective Record of Systematic Reviews (PROSPERO 2018: CRD42018114275) before its implementation and is described in the Complementary Materials. The protocol and the final report were developed based on the Cochrane Handbook for Systematic Reviews of Diagnostic Test Accuracy ${ }^{28}$.

\section{Review question}

What is the diagnostic accuracy of ELISAs with novel antigens compared to the standard serological test based on soluble antigens of Leishmania species (SLA) for the serological diagnosis of American Tegumentary Leishmaniasis (ATL)?

\section{Inclusion and exclusion criteria}

This review considered studies that included patients with ATL that were diagnosed by at least one of the parasitological gold standards (Montenegro skin test, direct microscopy of smears and/or culture) or by the Polymerase Chain Reaction (PCR). In addition, we included studies that evaluated the diagnostic accuracy of ELISAs based on novel antigens for the serological diagnosis of ATL, as well as those using soluble Leishmania antigens (SLA) in order to detect antibodies against species of Leishmania that cause 
ATL. Studies that analyzed the accuracy of ELISAs but did not define the endemic controls were excluded.

\section{Types of study}

Cross-sectional studies based on diagnosis by serological tests providing detailed measurements of sensitivity, specificity, positive and negative predictive values, likelihood ratio and area under the curve (AUC), were included.

\section{Search strategy}

An initial search limited to MEDLINE was performed by using the MeSH index terms and related keywords. This search was performed followed by the analysis of words along the text that were also mentioned in the titles and summaries and terms of the index used to describe the studies. A second search using all the identified keywords and index terms was performed on all included databases. In a third search, the reference list of all dissertation theses with clearly detailed accuracy values were evaluated. Considering that ATL is a disease that affects the American continent, the search was limited to English, Spanish and Portuguese. The search for primary literature was not limited to the initial date and was completed in October 2018.

The search for studies used the following databases: PubMed, Regional Portal of the Virtual Health Library (BVS), Brazilian Society of Dermatology, Virtual Health Library (IBECS), Literature in the Health Sciences in Latin America and the Caribbean (LILACS), Medical Literature Analysis and Retrieval System Online (Medline), Elsevier Embase, Cochrane Library, The National Institute for Health and Care Excellence (NICE), and Cumulative Index to Nursing and Allied Health Literature (CINAHL). The MeSH Index Terms searched were: Leishmaniasis, cutaneous Leishmaniasis, Mucocutaneous; ELISA; Serological, Test; Diagnosis; Leishmania; Serology; Data Accuracy. The keywords used were: "American Tegumentary Leishmaniasis, Serodiagnosis, Specificity and Sensitivity. The terms were combined via the boolean operators "AND" and/or "OR" to compose the search strings.

\section{Methodological quality assessment}

The articles selected for data collection were read by two independent reviewers to evaluate the methodological validity of each text before their inclusion in this review. The standardized critical evaluation instrument QUADAS 2 was used, which was released in 2011 after the revision of the original QUADAS (Quality Assessment of Diagnostic Accuracy Studies) ${ }^{29,30}$. All disagreements between reviewers were resolved through discussion or by a third reviewer.

\section{Data extraction}

Quantitative data were extracted from the texts included in this review using the STARD (Standards for Reporting Studies of Diagnostic Accuracy) checklist ${ }^{31}$. All disagreements between both reviewers were resolved through discussion or by a third reviewer.

\section{Data synthesis}

The results are shown in three groups: 1) Novel-based ELISA (novel antigens); 2) SLA-based ELISA (soluble antigens of Leishmania) and 3) immunofluorescence assays (IFA). The development of a meta-analysis to analyze the general performance of the tests was not performed as there was only one study for each ELISA based on a given novel antigen and also due to a great heterogeneity in the standard ELISA based on SLA. Data found in this study will be shown only in a narrative and qualitative way.

\section{RESULTS}

Our research resulted in 315 manuscripts related to the serology of leishmaniasis by the combined application of descriptors in the databases described above. Only 14 studies remained (Table 1) 20,22,24,25,27,32-40 after applying the eligibility criteria (duplicate texts, articles related to other topics, texts excluded due to review or quality method criteria). The studies evaluated the diagnostic accuracy of different specific and novel antigens. The function of some of these antigens are not known, for instance conserved hypothetical proteins such as rLiHyS, rLbHyM, LiHypA and LbrM.30.3350. Other antigens are heat shock proteins (HSP),rLb8E, rLb6H and HSP83.1, histaminereleasing factor (HRF), cytochrome C oxidase VII (CcOx), tryparedoxin peroxidase, eukaryotic initiation factor 5a, enolase, and $\gamma$-Tubulin. These assays were compared to standard ELISAs using soluble antigens from different Leishmania species (SLA), enriched membrane fraction and indirect immunofluorescence (IFA) assays. The results of our search strategy are shown in a PRISMA flowchart (Figure 1).

The methodological quality assessment revealed that the studies included in this systematic review had a "low risk of bias" in the domains of patient selection, index test, reference standard as well as flow and timing. Regarding 
Table 1 - A summary of the included studies.

\begin{tabular}{|c|c|c|c|c|c|c|}
\hline \multirow{2}{*}{ Journal } & \multirow{2}{*}{ Year } & \multirow{2}{*}{ Author } & \multicolumn{2}{|c|}{ Samples } & \multirow{2}{*}{ EC } & \multirow{2}{*}{ CD } \\
\hline & & & CL & ML & & \\
\hline Parasitol Int. & 2018 & Dias DS & 0 & 23 & 35 & 235 \\
\hline Parasitol Res. & 2017 & Lima MP & 20 & 25 & 25 & 10 \\
\hline Clin Microbiol. & 2017 & Sato $\mathrm{CM}$ & \multicolumn{2}{|c|}{219} & 68 & 91 \\
\hline Cell Immunol. & 2017 & Carvalho AMRS & 27 & 30 & 40 & 15 \\
\hline Vet Parasitol. & 2016 & Coelho EA & 12 & 12 & 20 & 8 \\
\hline Clin Vaccine Immunol. & 2015 & Duarte MC & 23 & 20 & 30 & 10 \\
\hline Braz J Infect Dis. & 2015 & Soares KA & \multicolumn{2}{|c|}{98} & 80 & 24 \\
\hline Clin Vaccine Immunol. & 2014 & Menezes-Souza D & 45 & 20 & 50 & 20 \\
\hline J Clin Lab Anal. & 2010 & Cataldo Jl & \multicolumn{2}{|c|}{76} & 76 & 0 \\
\hline Braz J Infect Dis. & 2009 & Szargiki R & \multicolumn{2}{|c|}{87} & 13 & 10 \\
\hline J Clin Lab Anal. & 2009 & Nascimento LD & \multicolumn{2}{|c|}{189} & 189 & 0 \\
\hline Trans R Soc Trop Med Hyg. & 2009 & Barroso-Freitas APT & 74 & 20 & 92 & 0 \\
\hline Acta Trop. & 2008 & Vidigal $\mathrm{C}$ de $\mathrm{P}$ & \multicolumn{2}{|c|}{48} & 48 & 30 \\
\hline Bol Malariol Salud Ambient. & 2007 & Añez N & \multicolumn{2}{|c|}{87} & 104 & 0 \\
\hline
\end{tabular}

$\mathrm{EC}=$ Endemic control; $\mathrm{CD}=$ Serum samples from Chagas Disease patients; $\mathrm{NI}=$ Not Included; $\mathrm{CL}=\mathrm{Cutaneous} \mathrm{Leishmaniasis;}$ $\mathrm{ML}=$ Mucosal Leishmaniasis.

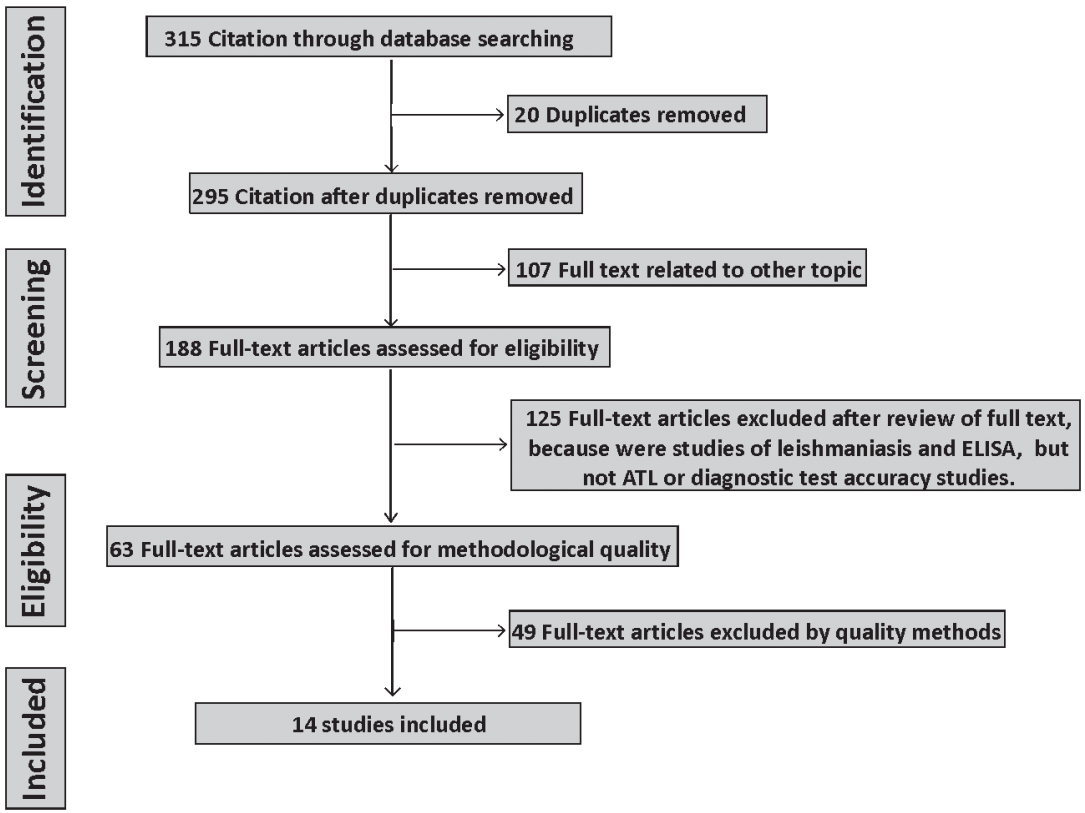

Figure 1 - A flowchart of the steps performed in the systematic review.

the "applicability concerns," the selected studies showed a low concern in the domains of patient selection, index test and reference standard (Figure 2). Data extracted from the final selection are shown in Table 2.

In the 14 studies included in this systematic review, 2,478 ELISAs were distributed among 1,155 (46.6\%) samples from patients with ATL, 870 (35.1\%) were endemic controls and $453(18.3 \%)$ analyses were evaluated cross- reactions with serum samples from patients with Chagas disease. Only seven studies distributed the samples of patients with ATL according to the clinical form of the disease into the categories cutaneous leishmaniasis (CL) and muco-cutaneous leishmaniasis (MCL) (Table 1). Regarding the comparisons with IFA, 417 tests were performed in only two studies. It is important to mention that cross-reactions with other dermatological diseases were also analyzed in 


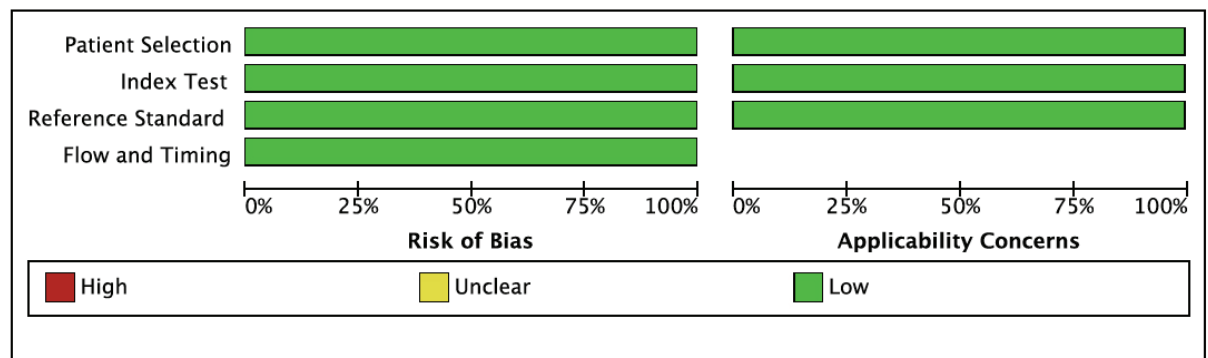

Figure 2 - Assessment of methodological quality domains in all the studies. Proportions of studies rated as "high," "unclear," and "low" are presented.

Table 2 - PRISMA checklist.

\begin{tabular}{|c|c|c|c|}
\hline Section/topic & \# & Checklist item & Reported on page \# \\
\hline \multicolumn{4}{|c|}{ TITLE } \\
\hline Title & 1 & Identify the report as a systematic review, meta-analysis, or both. & Title \\
\hline \multicolumn{4}{|c|}{ ABSTRACT } \\
\hline $\begin{array}{l}\text { Structured } \\
\text { summary }\end{array}$ & 2 & $\begin{array}{l}\text { Provide a structured summary including, as applicable: background; objectives; data } \\
\text { sources; study eligibility criteria, participants and interventions; study appraisal and } \\
\text { synthesis methods; results; limitations; conclusions and implications of key findings; } \\
\text { systematic review registration number. }\end{array}$ & Abstract \\
\hline \multicolumn{4}{|c|}{ INTRODUCTION } \\
\hline Rationale & 3 & Describe the rationale for the review in the context of what is already known. & Introduction \\
\hline Objectives & 4 & $\begin{array}{l}\text { Provide an explicit statement of questions being addressed with reference to } \\
\text { participants, interventions, comparisons, outcomes and study design (PICOS). }\end{array}$ & $\begin{array}{l}\text { Introduction and } \\
\text { Methods: } \\
\text { Review Question. }\end{array}$ \\
\hline \multicolumn{4}{|c|}{ METHODS } \\
\hline $\begin{array}{l}\text { Protocol and } \\
\text { registration }\end{array}$ & 5 & $\begin{array}{l}\text { Indicate if a review protocol exists, if and where it can be accessed (e.g., Web } \\
\text { address), and if available, provide registration information including registration } \\
\text { number. }\end{array}$ & Methods \\
\hline Eligibility criteria & 6 & $\begin{array}{l}\text { Specify study characteristics (e.g., PICOS, length of follow-up) and report } \\
\text { characteristics (e.g., years considered, language, publication status) used as criteria } \\
\text { for eligibility, giving rationale. }\end{array}$ & $\begin{array}{l}\text { Methods: } \\
\text { Inclusion Criteria }\end{array}$ \\
\hline $\begin{array}{l}\text { Information } \\
\text { sources }\end{array}$ & 7 & $\begin{array}{l}\text { Describe all information sources (e.g., databases with dates of coverage, contact } \\
\text { with study authors to identify additional studies) in the search and date last searched. }\end{array}$ & $\begin{array}{l}\text { Methods: } \\
\text { Search Strategy }\end{array}$ \\
\hline Search & 8 & $\begin{array}{l}\text { Present full electronic search strategy for at least one database, including any limits } \\
\text { used, so that that it could be repeated. }\end{array}$ & $\begin{array}{l}\text { Methods: } \\
\text { Search Strategy }\end{array}$ \\
\hline Study selection & 9 & $\begin{array}{l}\text { State the process for selecting studies (i.e., screening, eligibility, included in } \\
\text { systematic review and, if applicable, included in the meta-analysis). }\end{array}$ & $\begin{array}{l}\text { Methods: } \\
\text { Study Strategy }\end{array}$ \\
\hline $\begin{array}{l}\text { Data collection } \\
\text { process }\end{array}$ & 10 & $\begin{array}{l}\text { Describe method of data extraction from reports (e.g., piloted forms, independently, } \\
\text { in duplicate) and any processes for obtaining and confirming the data obtained by } \\
\text { investigators. }\end{array}$ & $\begin{array}{l}\text { Methods: } \\
\text { Data extraction }\end{array}$ \\
\hline Data items & 11 & $\begin{array}{l}\text { List and define all variables for which data were sought (e.g., PICOS, funding } \\
\text { sources) and any assumptions and simplifications made. }\end{array}$ & $\begin{array}{l}\text { Methods: } \\
\text { Data extraction/ } \\
\text { Quality assessment }\end{array}$ \\
\hline $\begin{array}{l}\text { Risk of bias in } \\
\text { individual studies }\end{array}$ & 12 & $\begin{array}{l}\text { Describe methods used for assessing risk of bias of individual studies (including } \\
\text { specification of whether this was performed in the study or outcome level), and how } \\
\text { this information is to be used in any data synthesis. }\end{array}$ & NA \\
\hline $\begin{array}{l}\text { Summary } \\
\text { measures }\end{array}$ & 13 & State the principal summary measures (e.g., risk ratio, difference in means). & NA \\
\hline $\begin{array}{l}\text { Synthesis of } \\
\text { results }\end{array}$ & 14 & $\begin{array}{l}\text { Describe the methods of handling data and combining results of studies, if done, } \\
\text { including measures of consistency }\left(e . g ., I^{2}\right) \text { for each meta-analysis. }\end{array}$ & NA \\
\hline $\begin{array}{l}\text { Risk of bias } \\
\text { across studies }\end{array}$ & 15 & $\begin{array}{l}\text { Specify any assessment of risk of bias that may affect the cumulative evidence (e.g., } \\
\text { publication bias, selective reporting within studies). }\end{array}$ & NA \\
\hline
\end{tabular}


Table 2 - PRISMA checklist.

\begin{tabular}{|c|c|c|c|}
\hline Section/topic & \# & Checklist item & Reported on page \# \\
\hline $\begin{array}{l}\text { Additional } \\
\text { analyses }\end{array}$ & 16 & $\begin{array}{l}\text { Describe methods of additional analyses (e.g., sensitivity or subgroup analyses, } \\
\text { meta-regression), if done, indicating which were pre-specified. }\end{array}$ & $\begin{array}{l}\text { Methods: } \\
\text { Data Synthesis }\end{array}$ \\
\hline \multicolumn{4}{|c|}{ RESULTS } \\
\hline Study selection & 17 & $\begin{array}{l}\text { Give numbers of studies screened, assessed for eligibility, and included in the review, } \\
\text { with reasons for exclusions at each stage, ideally with a flow diagram. }\end{array}$ & Results (Figure 1) \\
\hline $\begin{array}{l}\text { Study } \\
\text { characteristics }\end{array}$ & 18 & $\begin{array}{l}\text { For each study, present characteristics for which data were extracted (e.g., study } \\
\text { size, PICOS, follow-up period) and provide the citations. }\end{array}$ & Results (Table 1) \\
\hline $\begin{array}{l}\text { Risk of bias within } \\
\text { studies }\end{array}$ & 19 & $\begin{array}{l}\text { Present data on risk of bias of each study and, if available, any outcome level } \\
\text { assessment (see item 12). }\end{array}$ & NA \\
\hline $\begin{array}{l}\text { Results of } \\
\text { individual studies }\end{array}$ & 20 & $\begin{array}{l}\text { For all outcomes considered (benefits or harms), present, for each study: (a) simple } \\
\text { summary data for each intervention group (b) effect estimates and confidence } \\
\text { intervals, ideally with a forest plot. }\end{array}$ & $\begin{array}{l}\text { Results: } \\
\text { Figure } 2 \text { and } 3\end{array}$ \\
\hline $\begin{array}{l}\text { Synthesis of } \\
\text { results }\end{array}$ & 21 & $\begin{array}{l}\text { Present results of each meta-analysis done, including confidence intervals and } \\
\text { measures of consistency. }\end{array}$ & NA \\
\hline $\begin{array}{l}\text { Risk of bias } \\
\text { across studies }\end{array}$ & 22 & Present results of any assessment of risk of bias across studies (see Item 15). & NA \\
\hline Additional analysis & 23 & $\begin{array}{l}\text { Give results of additional analyses, if done (e.g., sensitivity or subgroup analyses, } \\
\text { meta-regression [see Item 16]). }\end{array}$ & Results \\
\hline \multicolumn{4}{|c|}{ DISCUSSION } \\
\hline $\begin{array}{l}\text { Summary of } \\
\text { evidence }\end{array}$ & 24 & $\begin{array}{l}\text { Summarize the main findings including the strength of evidence for each main } \\
\text { outcome; consider their relevance to key groups (e.g., healthcare providers, users, } \\
\text { and policy makers). }\end{array}$ & Discussion \\
\hline Limitations & 25 & $\begin{array}{l}\text { Discuss limitations at study and outcome levels (e.g., risk of bias), and at review- } \\
\text { level (e.g., incomplete retrieval of identified research, reporting bias). }\end{array}$ & Discussion \\
\hline Conclusions & 26 & $\begin{array}{l}\text { Provide a general interpretation of the results in the context of other evidence and } \\
\text { implications for future research. }\end{array}$ & Conclusion \\
\hline \multicolumn{4}{|c|}{ FUNDING } \\
\hline Funding & 27 & $\begin{array}{l}\text { Describe sources of funding for the systematic review and other support (e.g., supply } \\
\text { of data); role of funders for the systematic review. }\end{array}$ & NA \\
\hline
\end{tabular}

NA $=$ Not Applicable. Data collected on Prisma ${ }^{42}$

a few of the included studies (histoplasmosis, malaria, paracoccidioidomycosis, toxoplasmosis, tuberculosis, and leprosy). Regarding the geographic distribution, $89.6 \%$ of the samples were collected in Brazil and only $10.4 \%$ in Venezuela.

\section{Synthesized measurements of accuracy}

A global estimate of the accuracy of ELISAs used as serological methods in the diagnosis of ATL was summarized.

Based on recombinant antigens and other known proteins, novel antigens (HSP, rLb8E, rLb6H, HRF, LiHypA, CcOx, trypidoxin peroxidase, eukaryotic initiation factor 5, enolase and $\gamma$-tubulin) and standard SLA-based ELISAs were compared (Table 3).

In novel-based ELISAs, only four studies calculated the positive and negative predictive values (PPV and NPV), two calculated the likelihood ratio (LR), three calculated the percentage of accuracy and three the area under the curve (AUC). Regarding SLA-based ELISA tests, in nine studies, the positive and negative predictive values were calculated, the likelihood ratio by two, the percentage of accuracy by three and the AUC by two. Finally, in the two studies that compared IFA methods, the PPV and NPV were calculated (Table 3).

The novel-based ELISAs showed a sensitivity between 93.8-100\% and a specificity between $82.5-100 \%$, with equally high confidence intervals (CI) of $95 \%$ (Figure 3 ). The PPV showed values between $98.3-100 \%$ and NPV was $100 \%$ in the five studies that calculated these data. The accuracy percentage was between 90.4-100\%, and the AUC values were between $0.989-1$. The LR values reported in two studies were 50 and 55 (Table 3).

The SLA-based ELISAs showed an inconsistent and poor performance, with a range of sensitivity between 


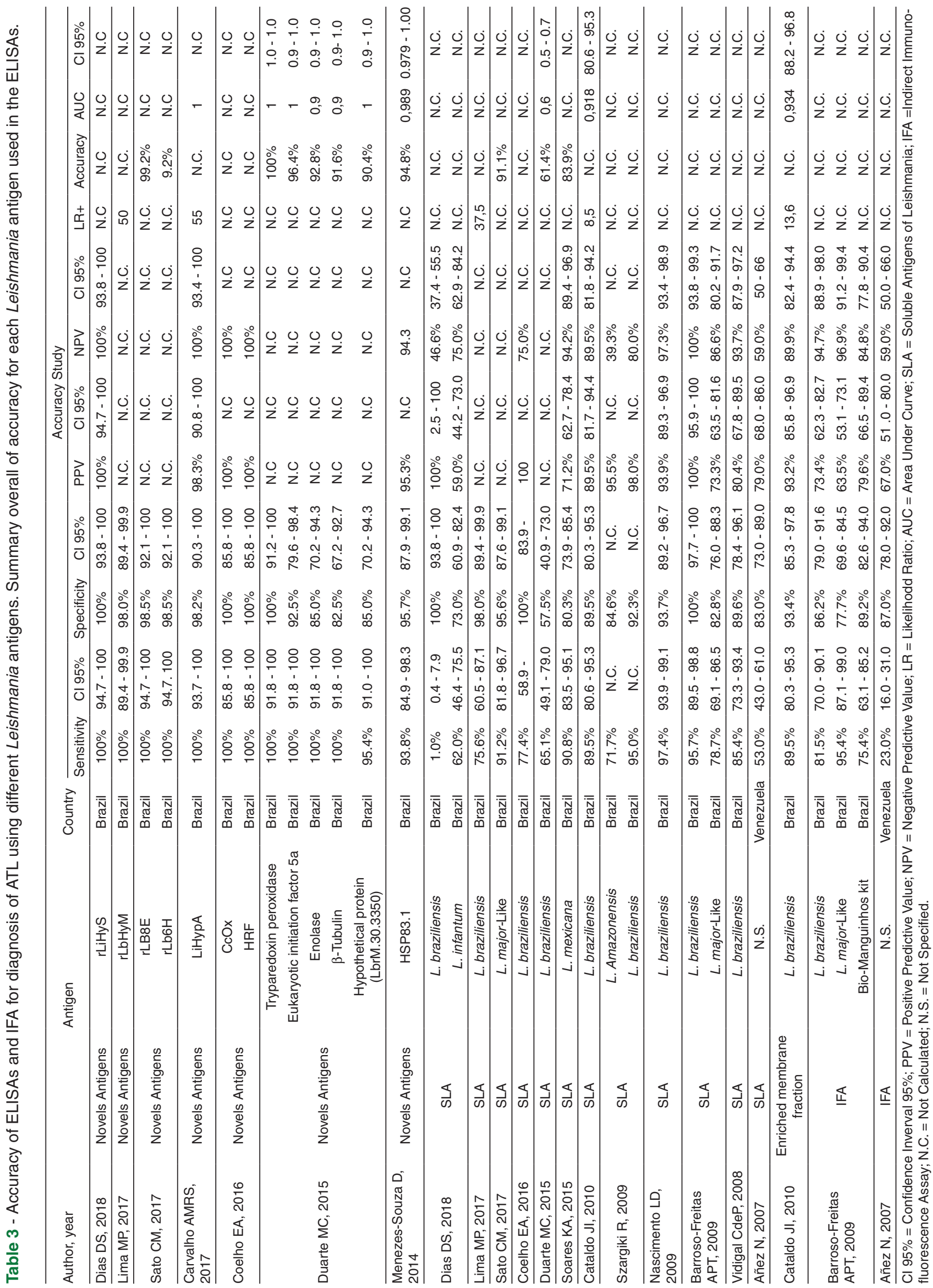




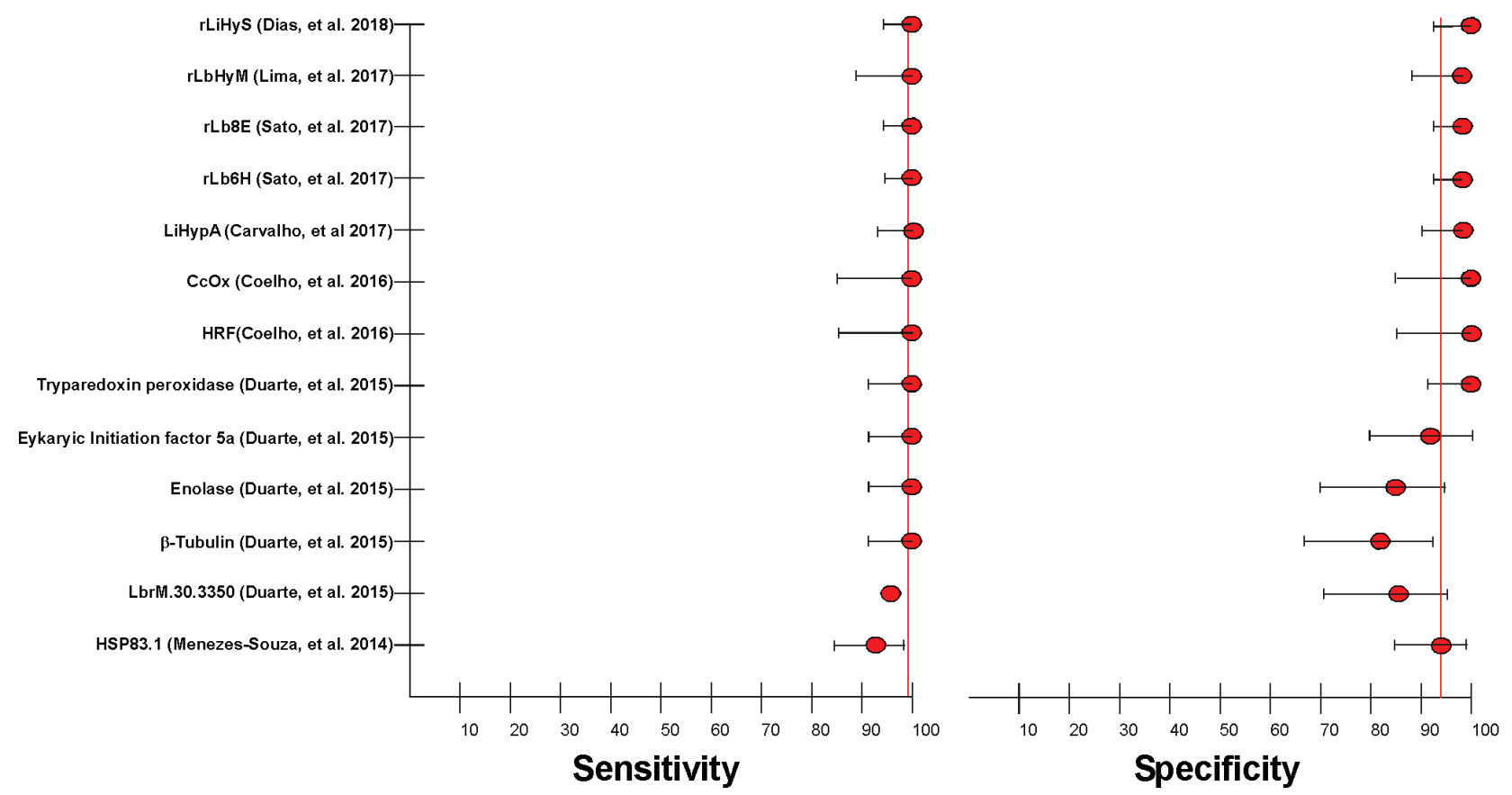

Figure 3 - Summary of sensitivity and specificity values of the novel-based ELISAs reported for each antigen.

$1-97.4 \%$, and a specificity between $57.5-100 \%$, with equally heterogeneous CI 95\% (Figure 4). The PPV values ranged from 59- 100\% and the NPV values ranged from 39.3-100\%. The accuracy percentage ranged from $61.4-91.1 \%$ and the two AUC measured were 0.6 and 0.989 . The reported LR values were 8.5 and $37.5 \%$ (Table 3 ).
A single study used Enriched Membrane Fraction and reported sensitivity and specificity of $89.5 \%$ and $93.4 \%$, respectively. In addition, PPV (93.2\%), NPV (89.9\%), LR (13.6) and AUC (0.934) were also reported (Table 3).

Regarding the accuracy of SLA-based ELISAs by leishmania species, L. (V.) braziliensis antigens were the

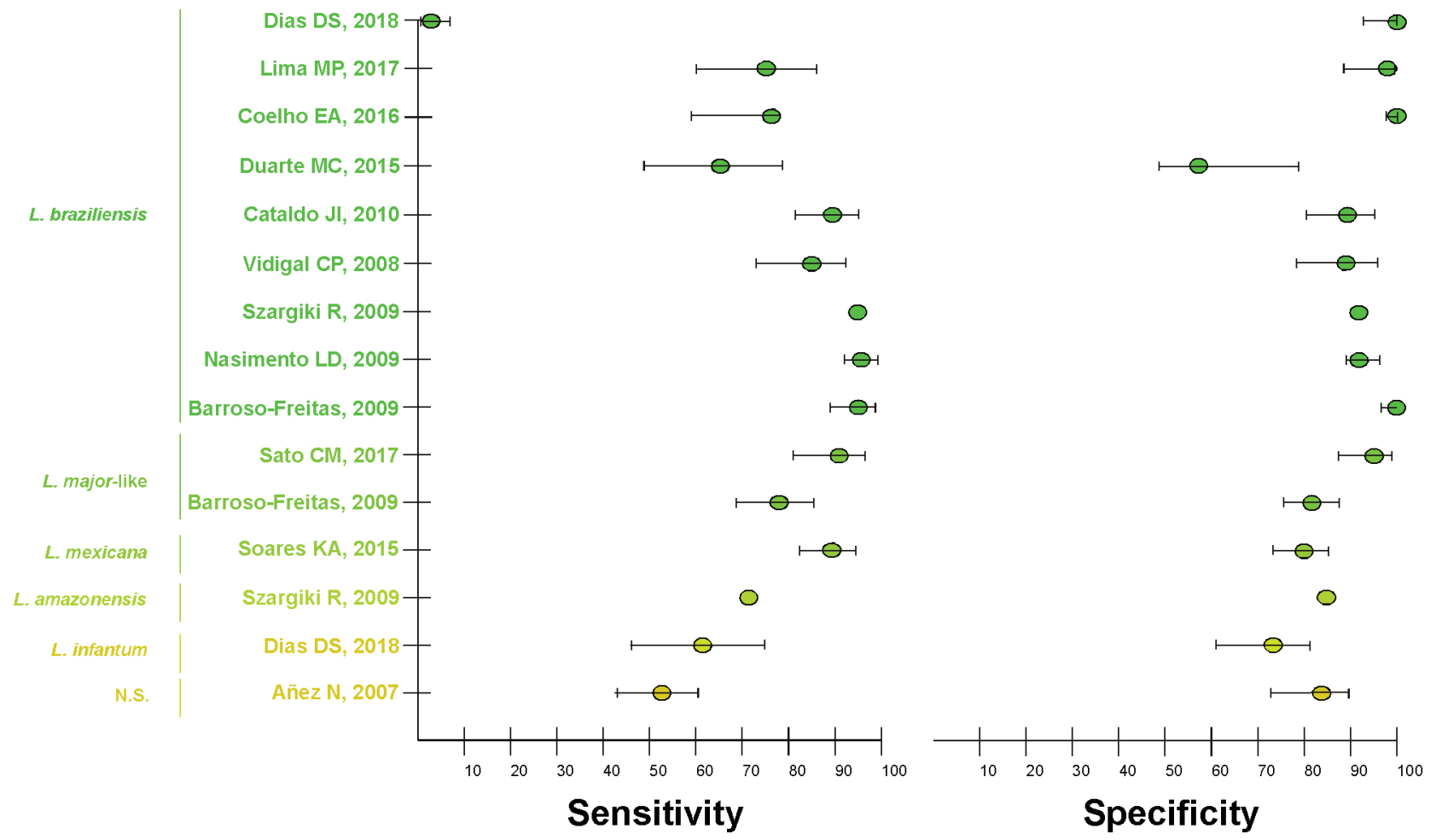

Figure 4 - Summary of sensitivity and specificity values of standard ELISA assays based on soluble antigen of specific Leishmania species. Observation: the author did not specify the Leishmania specie used. 
most used, showing values from 1-95.7\% of sensitivity and $57.5-100 \%$ of specificity. Two studies used $L$. (L.) majorlike and reported values of $85.4-91.2 \%$ of sensitivity and 82.8- 95.6\% of specificity. $L$. (L.) mexicana $90.8-80.3 \%$, L. (L.) amazonensis $71.7-84.6 \%$ and $L$. (L.) infantum $62-73 \%$, respectively.

The IFA tests were performed using different species of Leishmania (L. braziliensis, L. major-Like, BioManguinhos commercial antigen and another that was not specified). Regarding the diagnostic performance of IFAs. These tests showed a sensitivity between $23-95.4 \%$ and a specificity between 77.7- 89.2\%. The PPV values ranged from $63 .-79.6 \%$ and the NPV values ranged from 69- $96.9 \%$ (Table 3 ).

\section{Cross-reactivity with Chagas disease}

Ten studies performed comparisons of cross-reactions with serum samples from patients with Chagas disease, and only two reported reactivity (lack of specificity). Among the studies analyzing ELISAs with novel antigens, only one reported $17 \%$ (95\% CI, 12-27.9) of reactivity in ELISAs based on the recombinant rLb6H antigen ${ }^{27}$. As for standard ELISAs based on SLA, several percentages of cross-reactivity were reported according to the species used: L. major-Like $69 \%$ (95\% CI, 66.1 - 83.5 $)^{27}$, L. mexicana $66.7 \%{ }^{35}$, L. amazonensis $10 \%$ and L. braziliensis $20 \%{ }^{36}$.

\section{DISCUSSION}

Our research shows data that point to a problem regarding the choice of serological methods for the diagnosis of ATL. Several ELISAs using different types of antigens, have been proposed as sensitive tools for the diagnosis of this disease. From the available literature, we analyzed and summarized data on diagnostic accuracy studies of ELISAs based on novel antigens, some of them recombinants. They were compared with standard ELISAs based on soluble Leishmania antigens (SLA). Due to the existence of only one study per novel antigen, a metaanalysis was not conducted in this review as at least four studies are necessary to perform a meta-analysis.

Our research question was restricted to the Americas aiming to produce useful evidence for ATL control programs in the region. Since $92.2 \%$ of ELISAs included in this systematic review were developed in Brazil and the remaining $7.8 \%$ in Venezuela, our results reflect the state of serological diagnostic tests for ATL in Brazil.

Several indicators of diagnostic performance were proposed, such as the percentage of sensitivity and specificity. Novel ELISA antigens showed a high sensitivity and specificity, proving a better diagnostic performance than standard ELISAs (SLA), which showed heterogeneous values. However, the use of paired indicators (sensitivity and specificity) can create a bias when the performance of competing tests is performed, especially if one test does not outperform the other with respect to both indicators. Through a meta-analysis, the diagnostic odds ratio (DOR), which is the only indicator of diagnostic performance, would help to evaluate the diagnostic test performance in the studies objectively ${ }^{41}$.

Regarding SLA, the soluble antigens of $L$. (V.) braziliensis showed a better performance than the soluble antigens of the other species used in the serological diagnosis of LTA. In IFA tests, sensitivity and specificity values were similar to those observed in standard ELISAs (SLA). This could be explained by the fact that both, SLA-based ELISAs and IFAs were developed using the same Leishmania species.

From the total of 14 studies included in this systematic review, ten made comparisons on cross-reactions with serum samples from patients with Chagas disease, and only two reported the occurrence of cross-reactivity. The only novelbased ELISA that reported cross-reactivity was developed using $\mathrm{rLb} \mathrm{H}^{27}$. This recombinant antigen had a reactivity of $17 \%$, which is lower when compared to the $69 \%$ observed in the SLA-based ELISA of L. major-like and 33\% with $L$. (L.) mexicana. SLA-based ELISAs of $L$. amazonensis and $L$. braziliensis showed a lower or equal reactivity to $\mathrm{rLb} \mathrm{H}^{20}$.

The percentage of cross-reactivity to serum samples from patients with Chagas disease, in the serological methods used for the diagnosis of ATL, should be reported to estimate or at least to be aware of the probability of a cross-reactivity. For this reason, when using tests that show a high percentage of cross-reactivity for the diagnosis of ATL, the possibility of a coinfection with T. cruzi cannot be ruled out. Any suspicion of coinfection should be investigated using specific Chagas disease tests.

Using the genome sequencing, we can calculate the percentage of similarity of a target protein sequence among species of Leishmania and Trypanosoma cruzi before they are used as antigen in ELISAs to save time and resources.

There are some limitations in our study. First, the novel antigens as well as soluble antigens of different species of Leishamnia are different, resulting in different cut-off values. Second, although the specificity was almost $100 \%$, only a few authors included groups of control patients with diseases other than Chagas, such as tuberculosis, histoplasmosis, malaria and paracoccidioidomycosis. Finally, some studies included in this systematic review did not analyze positive and negative predictive values, and only a few showed values of likelihood ratio, area under the curve and accuracy. 
The lack of these data limited the comparison between the methods analyzed with regard to indicators such as sensitivity and specificity. Using paired indicators can be a disadvantage to compare the performance of competing tests, especially if one test does not outperform the other with respect to both indicators ${ }^{41}$. Both, sensitivity and specificity provide information about the probability of obtaining an accurate result (positive or negative) depending on the true condition of the patient with respect to the disease. However, PPV and NPV are useful in clinical practice informing the probability of the patient to be really sick or healthy according to a positive or negative result.

In this systematic review, the novel ELISAs antigens showed an advantage in sensitivity (95.4-100\%) and specificity (82.5-100\%) compared to standard ELISAs based on SLA (1\%-97.4\% and 57.5\%-100\%, respectively). These ELISAs based on SLA, together with IFAs showed heterogeneous accuracy values.

The development of new serological diagnostic tools, with higher accuracy and reliability in the diagnosis of ATL and capable of reducing the risk of cross-reactivity with Chagas disease or other infectious diseases is of great importance for laboratory diagnosis, analysis of treatment efficacy, epidemiology and disease control.

\section{AUTHORS' CONTRIBUTIONS}

AZ and CMS contributed with the analysis and interpretation of study data, in addition to the preparation of preliminary versions of this manuscript. FGLP contributed to the strategy of searching and analyzing data. SMBF contributed with data analysis and content review. OAE contributed with the design and delineation of the study, revision of the content and the approval of the final version of the manuscript. The authors approve the final version of the manuscript and are responsible for all its aspects.

\section{REFERENCES}

1. Ross R. Note on the bodies recently described by Leishman and Donovan.Br Med J. 1903;2:1261-2.

2. Gontijo B, Carvalho ML. Leishmaniose tegumentar americana. Rev Soc Bras Med Trop. 2003;36:71-80.

3. Copeland NK, Aronson NE. Leishmaniasis: treatment updates and clinical practice guidelines review. Curr Opin Infect Dis. 2015;28:426-37.

4. Goto H, Lindoso JA. Current diagnosis and treatment of cutaneous and mucocutaneous leishmaniasis. Expert Rev Anti Infect Ther. 2010;8:419-33.

5. Alvar J, Yactayo S, Bern C. Leishmaniasis and poverty. Trends Parasitol. 2006;22:552-7.
6. Alvar J, Vélez ID, Bern C, Herrero M, Desjeux P, Cano J, et al Leishmaniasis worldwide and global estimates of its incidence. PLoS One. 2012; 7:e35671.

7. Mathers CD, Ezzati M, Lopez AD. Measuring the burden of neglected tropical diseases: the global burden of disease framework. PLoS Negl Trop Dis. 2007;1:e114.

8. Galgamuwa LS, Dharmaratne SD, Iddawela D. Leishmaniasis in Sri Lanka: spatial distribution and seasonal variations from 2009 to 2016. Parasit Vectors, 2018;11:60.

9. World Healh Orgaization. Leishmaniasis in high-burden countries: an epidemiological update based on data reported in 2014. Wkly Epidemiol Rec. 2016;91:287-96.

10. Borges AF, Gomes RS, Ribeiro-Dias F. Leishmania (Viannia) guyanensis in tegumentary leishmaniasis. Pathog Dis. 2018;76:fty025

11. Brasil. Ministério da Saúde; Fundação Nacional de Saúde. Manual de controle da leishmaniose tegumentar americana. $5^{\mathrm{a}} \mathrm{ed}$. rev. Brasília: Ministério da Saúde; 2000.

12. Al-Jawabreh A, Dumaidi K, Ereqat S, Nasereddin A, Azmi $\mathrm{K}$, Al-Jawabreh $\mathrm{H}$, et al. A comparison of the efficiency of three sampling methods for use in the molecular and conventional diagnosis of cutaneous leishmaniasis. Acta Trop. 2018;182:173-7.

13. Boggild AK, Valencia BM, Veland N, Pilar Ramos A, Calderon F, Arevalo J, et al. Non-invasive cytology brush PCR diagnostic testing in mucosal leishmaniasis: superior performance to conventional biopsy with histopathology. PLoS One. 2011;6:e26395.

14. Manzur A, Bari Au. Sensitivity of leishmanin skin test in patients of acute cutaneous leishmaniasis. Dermatol Online J. 2006; $12: 2$.

15. Garcia AL, Kindt A, Quispe-Tintaya KW, Bermudez H, Llanos A, Arevalo J, et al. American tegumentary leishmaniasis: antigengene polymorphism, taxonomy and clinical pleomorphism. Infect Genet Evol. 2005;5:109-16.

16. Silva JG, Silva TM, Peloso EF, Machado-Coelho GL, Mayrink $\mathrm{W}$, Ariosa MC, et al. Comparison among three polymerase chain reaction assays on detection of DNA from Leishmania in biological samples from patients with American cutaneous leishmaniasis. Rev Soc Bras Med Trop. 2012;45:257-9.

17. Paiva-Cavalcanti M, Morais RC, Pessoa-e-Silva R, TrajanoSilva LA, Gonçalves-de-Albuquerque SC, Tavares DH, et al. Leishmaniases diagnosis: an update on the use of immunological and molecular tools. Cell Biosci. 2015;5:31.

18. Fonseca AM, Faria AR, Rodrigues FT, Nagem RA, Magalhães $\mathrm{RD}$, Cunha JL, et al. Evaluation of three recombinant Leishmania infantum antigens in human and canine visceral leishmaniasis diagnosis. Acta Trop. 2014;137:25-30.

19. Oliveira IQ, Silva RA, Sucupira MV, Silva ED, Reis AB, Grimaldi $\mathrm{Jr} \mathrm{G}$, et al. Multi-antigen print immunoassay (MAPIA)-based evaluation of novel recombinant Leishmania infantum antigens 
for the serodiagnosis of canine visceral leishmaniasis. Parasit Vectors. 2015;8:45.

20. Cataldo JI, Mello FC, Mouta-Confort E, Madeira MF, Schubach $\mathrm{AO}$, Genestra MS, et al. Immunoenzymatic assay for the diagnosis of American tegumentary leishmaniasis using soluble and membrane-enriched fractions from infectious Leishmania (Viannia) braziliensis. J Clin Lab Anal. 2010;24:289-94.

21. Georgiadou SP, Stefos A, Spanakos G, Skrimpas S, Makaritsis K, Sipsas NV, et al. Current clinical, laboratory, and treatment outcome characteristics of visceral leishmaniasis: results from a seven-year retrospective study in Greece. Int J Infect Dis. 2015;34:46-50.

22. Coelho EA, Costa LE, Lage DP, Martins VT, Garde E, Pereira $\mathrm{NC}$, et al. Evaluation of two recombinant leishmania proteins identified by an immunoproteomic approach as tools for the serodiagnosis of canine visceral and human tegumentary leishmaniasis. Vet Parasitol. 2016;215:63-71.

23. Abass E, Bollig N, Reinhard K, Camara B, Mansour D, Visekruna A, et al. rKLO8, a novel Leishmania donovani - derived recombinant immunodominant protein for sensitive detection of visceral leishmaniasis in Sudan. PLoS Negl Trop Dis. 2013; 7:e2322.

24. Lima MP, Costa LE, Duarte MC, Menezes-Souza D, Salles BC, Santos TT, et al. Evaluation of a hypothetical protein for serodiagnosis and as a potential marker for post-treatment serological evaluation of tegumentary leishmaniasis patients. Parasitol Res. 2017;116:1197-206.

25. Dias DS, Ribeiro PA, Salles BC, Santos TT, Ramos FF, Lage DP, et al. Serological diagnosis and prognostic of tegumentary and visceral leishmaniasis using a conserved leishmania hypothetical protein. Parasitol Int. 2018;67:344-50.

26. Celeste BJ, Arroyo Sanchez MC, Ramos-Sanchez EM, Castro LG, Lima Costa FA, Goto H. Recombinant leishmania infantum heat shock protein 83 for the serodiagnosis of cutaneous, mucosal, and visceral leishmaniases. Am J Trop Med Hyg. 2014;90:860-5.

27. Sato CM, Arroyo Sanchez MC, Celeste BJ, Duthie MS, Guderian $\mathrm{J}$, Reed SG, et al. Use of recombinant antigens for sensitive serodiagnosis of American tegumentary leishmaniasis caused by different leishmania species. J Clin Microbiol. 2017;55:495-503.

28. Higgins JP, Green S, editors. Cochrane handbook for systematic reviews of interventions: version 5.1.0. [cited 2019 Jul 17]. Available from: http://handbook-5-1.cochrane.org/

29. Whiting P, Rutjes AW, Reitsma JB, Bossuyt PM, Kleijnen J. The development of QUADAS: a tool for the quality assessment of studies of diagnostic accuracy included in systematic reviews. BMC Med Res Methodol. 2003;3:25.

30. Whiting PF, Rutjes AW, Westwood ME, Mallett S, Deeks JJ, Reitsma JB, et al. QUADAS-2: a revised tool for the quality assessment of diagnostic accuracy studies. Ann Intern Med. 2011;155:529-36.
31. Meyer GJ. Guidelines for reporting information in studies of diagnostic test accuracy: the STARD initiative. J Pers Assess. 2003;81:191-3.

32. Carvalho AM, Costa LE, Salles BC, Santos TT, Ramos FF, Lima MP, et al. An ELISA immunoassay employing a conserved Leishmania hypothetical protein for the serodiagnosis of visceral and tegumentary leishmaniasis in dogs and humans. Cell Immunol. 2017;318:42-8.

33. Soares KA, Urdapilleta AA, Santos GM, Carneiro AL, Gomes CM, Roselino AM, et al. Field validation of a Leishmania (Leishmania) mexicana exo-antigens ELISA for diagnosing tegumentary leishmaniasis in regions of Leishmania (Viannia) predominance. Braz J Infect Dis. 2015;19:302-7.

34. Menezes-Souza D, Mendes TA, Gomes MS, Reis-Cunha JL, Nagem RA, Carneiro CM, et al. Epitope mapping of the HSP83.1 protein of Leishmania braziliensis discloses novel targets for immunodiagnosis of tegumentary and visceral clinical forms of leishmaniasis. Clin Vaccine Immunol. 2014;21:949-59.

35. Duarte MC, Pimenta DC, Menezes-Souza D, Magalhaes RD, Diniz JL, Costa LE, et al. Proteins selected in Leishmania (Viannia) braziliensis by an immunoproteomic approach with potential serodiagnosis applications for tegumentary leishmaniasis. Clin Vaccine Immunol. 2015;22:1187-96.

36. Szargiki R, Castro EA, Luz E, Kowalthuk W, Machado AM, Thomaz-Soccol V. Comparison of serological and parasitological methods for cutaneous leishmaniasis diagnosis in the state of Parana, Brazil. Braz J Infect Dis. 2009;13:47-52.

37. Nascimento LD, Passos SR, Mouta-Confort E, Santiago MA, Alves AS, Madeira MF, et al. Comparative study of amplification systems in immunoenzyme assays for the diagnosis of American tegumentary leishmaniasis. J Clin Lab Anal. 2009;23:152-6.

38. Barroso-Freitas AP, Passos SR, Mouta-Confort E, Madeira MF, Schubach AO, Santos GP, et al. Accuracy of an ELISA and indirect immunofluorescence for the laboratory diagnosis of American tegumentary leishmaniasis. Trans R Soc Trop Med Hyg. 2009;103:383-9.

39. Vidigal CdeP, Marcussi VM, Marcussi LM, Mikcha JM, Arraes SM, Lonardoni MV, et al. Enzyme immunoassay using Leishmania (Viannia) braziliensis antigensfor laboratorial diagnosis of American cutaneous leishmaniasis. Acta Trop. 2008;107:208-12.

40. Añez N, Rojas A, Crisante G. Evaluation of conventional serological tests for the diagnosis of American cutaneous leishmaniasis. Bol Malariol Salud ambient. 2007;47:55-62.

41. Glas AS, Lijmer JG, Prins MH, Bonsel GJ, Bossuyt PM. The diagnostic odds ratio: a single indicator of test performance. J Clin Epidemiol. 2003;56:1129-35.

42. Ottawa Hospital Research Institute. PRISMA. [cited 2019 Aug 1]. Available from: http://www.prisma-statement.org/ 